\title{
Assessment of Oral Health Problems in Patients Receiving Orthodontic
} Treatment

\author{
Akshay Gupta* and Karanprakash Singh \\ Department of Orthodontics and Dentofacial Orthopaedics, Indira Gandhi Government Dental College and Hospital, Jammu and Kashmir, India
}

\begin{abstract}
Objective: To assess the problems faced by patients receiving orthodontic treatment as this procedure leads to more accumulation of plaque that effects oral health.
\end{abstract}

Methods: This epidemiological study was done among a group of 500 subjects consisting of 194 orthodontic and 306 non orthodontic patients. The age of all the participants ranges between 17 to 20 years with a mean age of 21.36 years. Clinical examination was done to know the presence of dental problems with orthodontic procedure. Data were analyzed with SPSS software version 16.0 at $p<0.05$.

Results: The dental problems noticed during the orthodontic procedure were oral ulcerations $(47.6 \%)$, caries $(34.3 \%)$ and periodontal diseases $(18.1 \%)$. Significant difference was found in case of calculus and shallow pocket component $(4-5 \mathrm{~mm})(\mathrm{p}<0.05)$ among both the groups. Overall significant difference of DMFT was surveyed among the groups with an increase in mean scores among orthodontic patients $(p<0.05)$.

Conclusion: The study showed high prevalence of dental problems in the orthodontic patients as they feel difficulty in maintaining their oral hygiene due to the inconvenience caused by orthodontic appliances.

Keywords: Orthodontic Patients; Dental caries; Periodontal diseases; Ulceration

\section{Introduction}

Orthodontic treatment helps the patients in improving dental and facial aesthetics; above all it also builds up self-esteem [1]. The main goal of this treatment is to improve dental occlusion and make teeth in proper alignment, which ultimately results in a good functioning of dentition [2].

Along with the benefits of orthodontic procedures, it has many complications which are faced by the patients undergoing treatment. Few studies explore such issues as pain, food accumulation under brackets and discomfort that may occur during treatment [3]. It is reported that $95 \%$ of the orthodontic patients experience varying degree of pain during orthodontic treatment [4]. Various studies have shown that problems associated with malocclusion such as traumatic oral ulcers, temporomandibular joint problems, and periodontal diseases $[1,5]$.

Throughout orthodontic treatment, both intra-oral and extra-oral tissues are at threat of injury. Arch wires, brackets, bands and long unsupported stretches of wire resting against the lips can also lead to ulcerations [6]. Excessive muscular activities of the cheek or tongue may also act as triggers for this [7].

Fixed orthodontic appliances may weaken plaque removal, proper oral hygiene, and overall affect the dental health [8]. Plaque accumulates on brackets and the resins used for bonding. Rapid demineralization has been found around orthodontic appliances even after one month of placement [7]. The formation of demineralization spots and pits increase the chances of caries [4]. The margins of orthodontic bands usually run along proximal to the subgingival area. Plaque accumulation in the subgingival bands and brackets can be a factor in the development of periodontal problems. Gingivitis may develop in patients who do not institute proper oral hygiene measures [9]. Patients often exhibit gingival hypertrophy, bleeding, increased plaque accumulation, and calculus formation during orthodontic treatment [10]. Thus, oral hygiene measures are recommended because bands, brackets, ligature wires, and elastics encourage the accumulation of microbial flora and food residues. In time, the plaque accumulation around orthodontic appliances may cause periodontitis and dental caries [11]. The objective of this study is to access the oral health complications faced by orthodontic patients.

\section{Methods}

A total of 194 orthodontic patients were examined from the Institution and different orthodontic clinics in the city during January to October 2014. For getting the valid results a group of non orthodontic patients (306) of similar age group were selected. This group was selected from the friends and atenders of orthodontic patients. So the total sample composed of 500 subjects, consisting of 204- boys and 296 - girls. The age of all the participants ranges between 17 to 20 years with a mean age of 21.36 years.

A verbal informed consent was taken from the participants and the privacy of the orthodontic practitioners was ensured after examining the patient. Before the commencement of study, a pilot study was done among 30 subjects to assess the prevalence of dental caries, periodontal diseases and oral ulcers in order to ensure the degree of repeatability (Cronbach's alpha $=0.78$ ).

\section{Inclusion criteria}

Those who were willing to participate and free from systemic diseases were included in the sample.

*Corresponding author: Akshay Gupta, Department of Orthodontics and Dentofacial Orthopaedics, Indira Gandhi Government Dental College and Hospital, Jammu and Kashmir, India, Tel: +918141787176; E-mail: akshayshivali.@gmail.com

Received December 25, 2014; Accepted January 14, 2015; Published January 19, 2015

Citation: Gupta A, Singh K (2015) Assessment of Oral Health Problems in Patients Receiving Orthodontic Treatment. Dentistry 5: 280. doi:10.4172/21611122.1000280

Copyright: ( 2015 Gupta A, et al. This is an open-access article distributed unde the terms of the Creative Commons Attribution License, which permits unrestricted use, distribution, and reproduction in any medium, provided the original author and source are credited. 


\section{Exclusion criteria}

Patients who were absent on the day of appointment were excluded

\section{Examination}

The proforma compiled of four components, the first part pertaining to the questions of demographic variables. The second, third and fourth part recorded information regarding dental caries status and periodontal diseases using WHO Oral Health Assessment Form (1997) [12]. Also the examination of oral ulcers was done.

The questionnaire was subjected to statistical analysis. Data were analyzed with SPSS software version 16.0 (SPSS Inc., Chicago, IL, USA). Quantitative values were compared using student's test and ANOVA test. Calculated values of the test criteria were compared with the tabular value at $95 \%$ confidence level to certain the significance of the test at $\mathrm{p}$ value of 0.05 .

\section{Results}

The dental problems came across during the orthodontic procedure were oral ulcerations (47.6\%), caries (34.3\%) and periodontal diseases (18.1\%). Most of the ulcers were traumatic caused by orthodontic wires i.e. $72.6 \%$ followed by apthous ulcers (27.4\%) (Figure 1) as mentioned in Graph 1.

The mean number of sextants according to different study groups confirmed that, all the component of periodontal disease namely bleeding, calculus, shallow and deep pockets were higher among orthodontic patients (Figure 2). But the significant difference was seen only in case of calculus and shallow pocket component (4-5 $\mathrm{mm})(\mathrm{p}<0.05)$. Among all the components of periodontal problems, a clear dominance of calculus was seen among orthodontic patients. The prevalence of deep pockets ( $6 \mathrm{~mm}$ or more) was unusually noticed in both the groups as $0.11 \pm 1.266$ among orthodontic study group and $0.04 \pm 1.212$ among non orthodontic ones (Table 1).

Overall significant difference of DMFT was surveyed among both the groups with an increase in mean scores among orthodontic patients $(\mathrm{p}<0.05)$. Correspondingly orthodontic group showed significantly higher prevalence of caries. But no significant results were obtained in case of missing teeth and filled teeth as illustrated in Table 2.

\section{Discussion}

Orthodontic treatment carries the risks of tissue damages. It is important that the practitioners are aware of these risks. The most common finding in this study was ulceration of soft mucosa and the

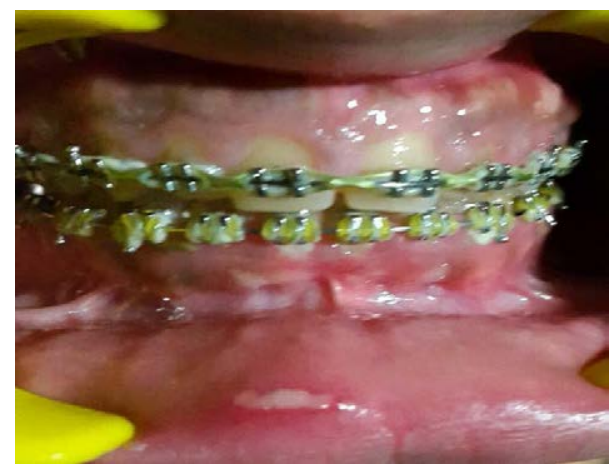

Figure 1: Oral ulceration with orthodontic appliances.

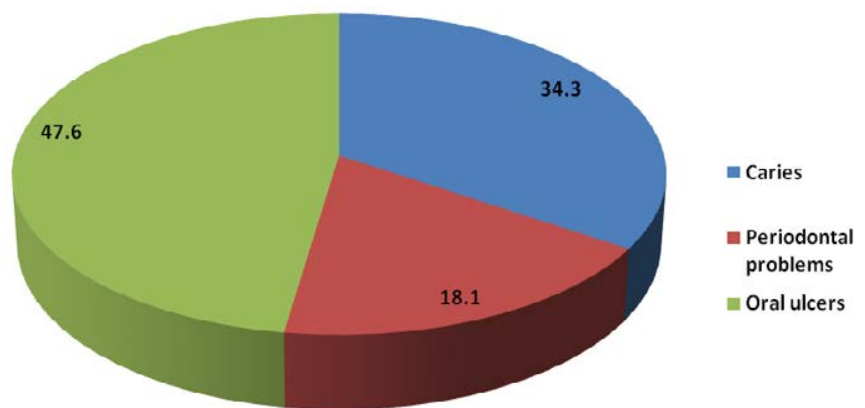

Graph 1: Frequency of oral problems encountered with orthodontic procedure.

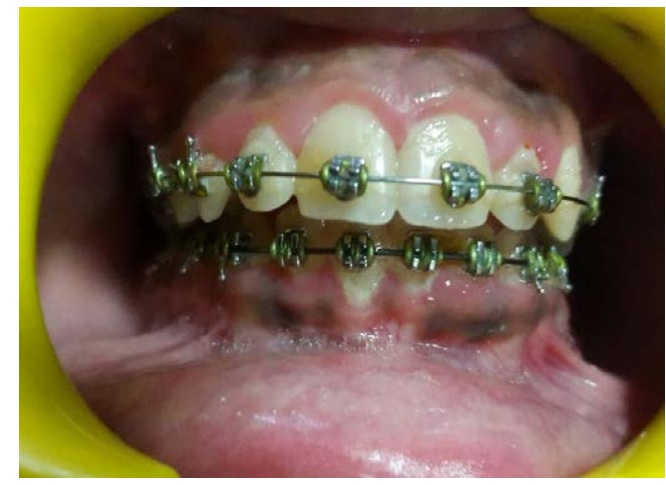

Figure 2: Gingivitis with orthodontic appliances.

\begin{tabular}{|c|c|c|c|c|c|}
\hline $\begin{array}{c}\text { Periodontal } \\
\text { disease }\end{array}$ & Groups & No & Mean & Std. Deviation & p-value \\
\hline Bleeding & Orthodontics & 194 & .97 & 1.273 & \multirow{2}{*}{.908} \\
\cline { 2 - 5 } & Non orthodontics & 306 & .94 & 1.249 & \\
\hline Calculus & Orthodontics & 194 & 1.08 & 1.664 & \multirow{2}{*}{.001} \\
\cline { 2 - 5 } & Non orthodontics & 306 & .98 & 1.303 & \\
\hline $\begin{array}{c}\text { Pocket } \\
(4-5 m m)\end{array}$ & Orthodontics & 194 & .19 & .529 & \multirow{2}{*}{.000} \\
\cline { 1 - 5 } & Non orthodontics & 306 & .07 & .346 & \\
\hline $\begin{array}{c}\text { Pocket } \\
(6 m m \text { or } \\
\text { more })\end{array}$ & Orthodontics & 194 & .11 & 1.266 & \multirow{2}{*}{.487} \\
\cline { 2 - 5 } & Non orthodontics & 306 & .04 & 1.212 & \\
\hline
\end{tabular}

Table 1: Prevalence of Periodontal disease among orthodontic and non-orthodontic patients.

\begin{tabular}{|c|c|c|c|c|c|}
\hline Components & Groups & No & Mean & Std. Deviation & Sig. \\
\hline \multirow{2}{*}{ Decayed teeth } & Orthodontics & 194 & 1.29 & 1.345 & \multirow{2}{*}{.000} \\
\cline { 2 - 6 } & Non orthodontics & 306 & .95 & 1.065 & \\
\hline \multirow{2}{*}{ Missing teeth } & Orthodontics & 194 & .26 & .566 & \multirow{2}{*}{.096} \\
\cline { 2 - 6 } & Non orthodontics & 306 & .23 & .559 & \\
\hline \multirow{2}{*}{ Filled teeth } & Orthodontics & 194 & .29 & .731 & \multirow{2}{*}{.297} \\
\cline { 2 - 6 } & Non orthodontics & 306 & .24 & .670 & \\
\hline \multirow{2}{*}{ DMFT } & Orthodontics & 194 & 1.85 & 1.736 & \multirow{2}{*}{.001} \\
\cline { 2 - 6 } & Non orthodontics & 306 & 1.41 & 1.482 & \\
\hline
\end{tabular}

Table 2: Prevalence of DT, MT, FT and DMFT among orthodontic and nonorthodontic patients.

results were consistent with other studies $[6,13]$. These patients get ulcers secondary to rubbing of the lips and cheeks on brackets and bands, as they become acclimatized to fixed orthodontic appliances [1]. 
During orthodontic procedure patients feel difficulty in maintaining their oral hygiene as teeth are malposed which cause inconvenience in cleaning. This leads to more accumulation of microorganisms in the oral cavity. Further microorganisms play an important role in the etiology of plaque that leads to periodontal diseases and caries which has been discussed in the literature since years. Plaque is a precursor of dental problems; and plaque retention sites are particularly prone to tooth decay and gum problems [14].

Hriday et al. reported high accumulation of plaque in orthodontic patients [15]. Various studies stated high prevalence of dental diseases among orthodontic patients which is also reflected in the present study $[14,16]$.

Dental Caries is the most common dental problem encountered [17]. The prevalence experienced in the study is higher than studies reported by Shailee et al. among 12 and 15 years school children in Shimla [18], Naidu et al. among children in Trinidad and Tobago [19], Petersen and Kaka among adults in Niger [20], Logan et al. in New Zealand [21], Martignon et al. reported DMF-S as 6.7 in 12-29 years Colombian subjects receiving fixed orthodontic treatment [16]. It is well established that orthodontic treatment is implicated for changing oral environment by providing retention sites for dental plaque and increases the risk of developing caries [14].

However Stahl et al. [22] found no positive correlation between prevalence of caries and malocclusion. Similarly, Nolting et al. [23] observed reduced DMFT scores after receiving orthodontic treatment possibly as a result of convenience in maintaining oral health.

In the present study, orthodontic patients were found with more periodontal problems. Similar results were shown by Ristic et al. in three months time after the fixed appliance was placed [24]. It was found that there is an increase in plaque and microbiological parameters with orthodontic appliances. The accumulation of plaque causes difficulty for patients to maintain their oral hygiene and worsen the periodontal status.

\section{Conclusion}

The results revealed higher prevalence of dental problems as oral ulcers, dental caries and periodontal diseases among orthodontic patients than non orthodontic ones. Orthodontic practitioners should advice their patients to maintain proper oral hygiene. Periodic evaluation must be done to diagnose these diseases at early stages for proper treatment.

\section{References}

1. Ellis PE, Benson PE (2002) Potential hazards of orthodontic treatment-what your patient should know. Dent Update 29: 492-496.

2. Fawzan AA (2013) Reasons for seeking orthodontic treatment in Qassim region: a Pilot Study. International Dental Journal of Student's Research 1: 52-68.

3. Petrone J, Fishell J, Berk NW, Kapur R, Sciote J, et al. (2003) Relationship of malocclusion severity and treatment fee to consumer's expectation of treatment outcome.Am J Orthod Dentofacial Orthop 124: 41-45.

4. Bos A, Hoogstraten J, Prahl-Andersen B (2005) Attitudes towards orthodontic treatment: a comparison of treated and untreated subjects.Eur $\mathrm{J}$ Orthod 27: 148-154.

5. Lew KK (1993) Attitudes and perceptions of adults towards orthodontic treatment in an Asian community.Community Dent Oral Epidemiol 21: 31-35.

6. Kvam E, Bondevik O, Gjerdet NR (1989) Traumatic ulcers and pain in adults during orthodontic treatment. Community Dent Oral Epidemiol 17: 154-157.

7. Profit WR (2007) Orthodontic treatment planning: Limitations, Controversies and special problems. Contemporary Orthodontics (4th edtn) Elsevier Science: 268-330.

8. Anhoury P, Nathanson D, Hughes CV, Socransky S, Feres M, et al. (2002) Microbial profile on metallic and ceramic bracket materials. Angle Orthod 72 338-343.

9. Türkkahraman H, Sayin MO, Bozkurt FY, Yetkin Z, Kaya S, et al. (2005) Archwire ligation techniques, microbial colonization, and periodontal status in orthodontically treated patients. Angle Orthod 75: 231-236.

10. Lo BA, Di Marco R, Milazzo I, Nicolosi D, Calì G, et al. (2008) Microbiological and clinical periodontal effects of fixed orthodontic appliances in pediatric patients.New Microbiol 31: 299-302.

11. Dhami B, Shrestha P, Shrestha RM, Dhakal J (2013) Assessment of Periodontal Health in Nepalese Orthodontic Patients. Orthodontic Journal of Nepal 3: 26 30.

12. World Health Organization (1987) Oral health surveys basic method (4th edtn) Geneva, WHO: 760-871.

13. Baricevic M, Mravak-Stipetic M, Majstorovic M, Baranovic M, Baricevic D, et al. (2011) Oral mucosal lesions during orthodontic treatment.Int J Paediatr Dent 21: 96-102.

14. Qazi HS, Azam S, Khurram MS, Zia AU (2011) Prevalence of dental caries in the permanent dentition of patients seeking orthodontic treatment in Bara Kahu. Pakistan Oral \& Dental Journal 31: 2

15. Hriday RP, Ahmed AH, Banu N, Kumar S, Kumar M, et al. (2012) Plaque, caries level and oral hygiene habits in patients receiving orthodontic treatment International Journal of Preventive Dentistry and Oral Epidemiology 1: 1-6.

16. Martignon S, Ekstrand KR, Lemos MI, Lozano MP, Higuera C (2010) Plaque, caries level and oral hygiene habits in young patients receiving orthodontic treatment. Community Dent Health. 3: 133-138.

17. Sogi G, Bhaskar DJ (2001) Dental caries and oral hygiene status of 13-14 year old school children of Davangere.J Indian Soc Pedod Prev Dent 19: 113-117.

18. Shailee F, Sogi GM, Sharma KR (2013) Association between Dental caries and body mass index among 12 and 15 years school children in Shimla, Himachal Pradesh. Journal of Advanced Oral Research 4: 8-14

19. Naidu R, Prevatt I, Simeon D (2006) The oral health and treatment needs of schoolchildren in Trinidad and Tobago: findings of a national survey. Int $J$ Paediatr Dent 16: 412-418.

20. Petersen PE, Kaka M (1999) Oral health status of children and adults in the Republic of Niger, Africa. Int Dent J 49: 159-164

21. Logan TP, Cutress TW, Garrett N, Trengrove HG (2009) Dental treatment profile of New Zealand Defence Force personnel. N Z Dent J 105: 77-81.

22. Stahl F, Grabowski R (2004) Malocclusion and caries prevalence: is there a connection in the primary and mixed dentitions? Clin Oral Investig 8: 86-90.

23. Nolting I, Michel K, Ruf S (2008) Dental health and orthodontic treatment need among dental students treated by certified orthodontists and general dental practitioners. Quintessence Int 39: 73-79.

24. Ristic M, Vlahovic Svabic M, Sasic M, Zelic O (2007) Clinical and microbiologica effects of fixed orthodontic appliances on periodontal tissues in adolescents Orthod Craniofac Res 10: 187-195. 